\title{
Superbug, an Emerging Global Threat in Current Scenario: A Review
}

\author{
Arpita Padhy ${ }^{1}$, Amit Ranjan Sahu ${ }^{2}$, Siddharth Ranabijuli ${ }^{3}$ and Subha Ganguly ${ }^{4} *$ \\ ${ }^{1}$ Additional Veterinary Assistant Surgeon, Department of Animal Husbandry and Veterinary Services, \\ Government of Odisha, India. \\ ${ }^{2} \mathrm{Ph} . \mathrm{D}$ Scholar, Division of Veterinary Biotechnology, Indian Veterinary Research Institute, Izatnagar, \\ Bareilly, U.P, India. \\ ${ }^{3}$ Subject Matter Specialist (Veterinary Science), Krishi Vigyan Kendra, Puri, OUAT \\ ${ }^{4}$ Associate Professor, Department of Veterinary Microbiology, Arawali Veterinary College (Affiliated \\ with Rajasthan University of Veterinary and Animal Sciences, Bikaner), N.H. - 52 Jaipur Road, \\ V.P.O. Bajor, Sikar, Rajasthan, India \\ *ganguly38@gmail.com
}

\begin{abstract}
Antibiotics have been used for chemotherapeutic purpose from the early part of the $19^{\text {th }}$ century. The development of antibiotics decreased the mortality among the human and animals leading to a better life expectancy. But the injudicious use of antimicrobials and selection pressure the microbes have developed resistance which became more prominent during last few decades. With the evolution of Methicilin-resistant Staphylococcus aureus (MRSA), Hospital-acquired MRSA, Community-acquired MRSA and MDR TB (Multidrug resistant tuberculosis) challenge for the clinicians have increased to a greater extent. Recent development in nanotechnology based drug delivery system may prove to be solution for combating these resistance bacteria. However policies and regulations for antibiotic use should be formulated to control the further development of resistance among the microbes.
\end{abstract}

Keywords: Antibiotic resistance, Diseases, MRSA, Multidrug resistance, Superbug.

\section{INTRODUCTION}

The use of antibiotics for combating the infectious agents dated back to the era of Alexander Flemming (1929). With the development of antibiotics to higher synthetics groups, came to fore the emergence of resistant microbes. Antibiotics are used for combating the infectious diseases but their excessive and misuse have given rise the formation of superbugs graving a major problem worldwide. Superbug is a term used to describe the newly evolved bacterial species resistant to antibiotics. This resistance to antibiotics by Super bugs causes economic losses by increasing the duration of infection, treatment cost and decreasing the success of surgical treatments due to hospital acquired infections. ${ }^{[1]}$ This morbidity and mortality loss caused there of indirectly hampers the economic developments in countries. The previous reports say that the cost of medical sectors for treating resistant bacterial infections and MDR TB (Multidrug resistant) reaches to 4-7 dollar billion per year ${ }^{[2]}$ and 180,000 dollar in United State ${ }^{[3]}$. In developing countries also the misuse and underuse of antimicrobials due to lack of awareness of patients, medical workers and financial problems emerged the antimicrobial resistant strains. ${ }^{[4,5]}$ Due to rapid globalization of human population by travel and other factors these resistant strains spread easily between developed and developing countries making it a global problem. ${ }^{[6,7]}$

\section{Chronological Discoveries of VARIOUS SUPERBugs}

Initially Drug-resistant strains were found on Hospitals due to use of most antibiotics. ${ }^{[8]}$ Staphylococcus aureus was the first resistant bug discovered in 1943 against Penicillin. ${ }^{[9]}$ In 1967, Streptococcus pneumoniae and after that the Enterococcus faecium was found resistant to Penicillin. ${ }^{[10]}$ After Penicilin, Methicillin was the target antibiotic and first Methicilin- resistant $S$. aureus (MRSA) was found in 1961 in UK and became a major bug worldwide in 1980s. ${ }^{[11]}$ After that both Hospital-acquired MRSA (HA-MRSA) ${ }^{[12]}$ and Community acquired MRSA (CA-MRSA) ${ }^{[13]}$ 
emerged creating problems worldwide. The first outbreak of CA-MRSA has occurred in the indigenous populations of Western Australia ${ }^{[14]}$ and after that it emerged worldwide. There after MRSA began to develop resistance against glycopeptides like Vancomycin leading to production of Vancomycin intermediately resistant $S$. aureus (VISA) and in 1997 its first case was isolated. ${ }^{[15,16]}$ Resistant gram-negative bugs emerged simultaneously with gram-positive strains. Multidrug resistance was first seen in enteric bacteria like Escherichia coli, Shigella and Salmonella in late 1950s-1960s. ${ }^{[17]}$ Extended-spectrum beta-lactamase containing bugs prevailed in Europe and then worldwide $^{[18,19]}$ After that Carbapenemase-producing gram-negative bugs like extensively drugresistant Acinetobacter spp. and enterobacteriacae producing New-Delhi metallo-protease-1 (NDM-1) Klebsiella pneumoniae producing carbapenemases were emerged. ${ }^{[20]}$ In $21^{\text {st }}$ century many multidrug resistance bugs prevaled like Pseudomonas aeuroginosa, Mycobacterium tuberculosis strains resistant to four and more line of drugs specific for TB called as extremely drug resistant (XDR) strains ${ }^{[21,22]}$ and totally drug resistant (TDR) strains ${ }^{[23]}$ etc. First XDR isolate was discovered in 2001. ${ }^{[24]}$ Newer antibiotics are discovered to combat these resistant strains and simultaneously the bugs mutate their genes and by selection process become resistant to all drugs slowly causing challenge for physicians to treat infections. ${ }^{[25]}$

\section{MECHANISMS OF RESISTANCE TO ANTIBIOTICS BY DIFFERENT RESISTANT BUGS}

The prolonged administration or misuse of antimicrobials resulted in selection pressure which favors the evolution of resistant strains and subsequently their transmission causes spread of the resistant strains in the environment. The long-term use of a single antibiotic favored development of strains resistant to both same antibiotic along with other related antibiotics. ${ }^{[26]}$ The spread of resistance traits occurs among different ecological groups and taxonomical groups by the presence of mobile genetic elements like bacteriophage, plasmids, naked DNA, transposons etc.. ${ }^{[27,28]}$ Sequential Mutation of genes help in low to high levels of drug resistances. ${ }^{[29]}$ Due to the selection and mutation of genes these resistant strains hamper the easy passage of drugs through the cellwall, change their targets and inactivate them by producing enzymes. ${ }^{[30]}$ The gram positive super bugs like $S$. aureus resists to Methicillin and Vancomycin by changes in their cell wall and cell membrane while the resistance to Linezolid antibiotic attributed to the mutation of $23 \mathrm{~S}$ ribosomal RNA. ${ }^{[31]}$ It has been seen that like Gram positive bacteria Gram negative bugs like Pseudomonas, Klebsiella, Enterobacter and Acinetobacter resist various antibiotics in various ways. They resist the action of beta-lactam antibiotics by production of enzymes cephalosporinases, carbapenemases and extended spectrum beta-lactamases. By Mutation of target sites they resist the action of Fluoroquinolones and by modification of Aminoglycosides by bacterial enzymes they resist Aminoglycosides. ${ }^{[32,33]}$ MDR, XTR and TDR TB microorganisms show resistance to antibiotics by spontaneous mutation in various genes. ${ }^{[34]}$ Resistance to Macrolides and related antibiotics mostly occurs due to the $\mathrm{r}$ RNA modification responsible for their bindings with ribosomes. ${ }^{[35]}$

\section{PREVENTION AND CONTROL}

Antimicrobial resistant bugs are the emerging present day threats. The followings are some control and preventive measures should be taken to minimize their developments, spread and to promote development of new therapeutics.

- Most of the infections spread and occur from the contact of infected persons and lack of hygienic practices. Proper sanitation and hygiene maintenance in food and other things can reduce the spread of superbugs.

- Inappropriate use of antibiotics occurs due to unnecessary length of treatment, wrong prescription and its use without infections. ${ }^{[36]}$ Both physicians and people education about it can check the development of resistant strains.

- Some policies and regulations should be practiced in both developing and developed countries to check the unnecessary drug promotions. ${ }^{[37]}$

- Antibiotics are used vividly in food animals like chicken, cattle, pigs, agricultural fields and fish farming methods. These uses establish a direct link for the appearance of resistance in humans. ${ }^{[25,38]}$ Dusting of antibiotics as disease prophylaxis and use of antibiotic laden animal manure on croplands also contribute towards the development of resistant strains in 
environment. ${ }^{[39]}$ So measures should be taken to follow the WHO rules to minimize the dual-use antimicrobials ${ }^{[40]}$ which are both related to human beings and food promotions.

- Attempts should be taken to check the spread of antimicrobial resistances by restricting human to human transmission of resistant strains, decreasing the use of broad spectrum antimicrobial and developing new and novel antimicrobials. ${ }^{[41]}$

- Steps should be taken to prevent infections by inhibiting key gene products involved in the infection process. ${ }^{[42]}$

\section{Novel Newer Technologies to reduce the Superbugs}

$>$ Vivid research and application of Nanotechnology for identification of resistant bacteria ${ }^{[43]}$ and therapy for combating superbugs should be practiced ${ }^{[44]}$.

$>$ Ultraviolet- $\mathrm{C}$ irradiation is useful to reduce the load of MRSA in food and Beverage industry as well as in hospital rooms. Hydrogen peroxide vapour is also effective in Hospital wards to reduce the resistant bacteria. ${ }^{[45]}$

\section{REFERENCES}

[1] Kumarasamy K.K., M.A. Toleman, T.R. Walsh, J. Bagaria, F. Butt, R. Balakrishnan, U. Chaudhary, M. Doumith, C.G. Giske, S. Irfan, P. Krishnan, A.V. Kumar, S. Maharjan, S. Mushtaq, T. Noorie, D.L. Paterson, A. Pearson, C. Perry, R. Pike, B. Rao, U. Ray, J.B. Sarma, M. Sharma, E. Sheridan, M.A. Thirunarayan, J. Turton, S. Upadhyay, M. Warner, W. Welfare, D.M. Livermore, N. Woodford. 2010. Emergence of a new antibiotic resistance mechanism in India, Pakistan, and the UK: a molecular, biological, and epidemiological study. Lancet Infect Dis., 10: 597-602.

[2] John, J.F. and N.O. Fishman, 1997. Programmatic role of the Infectious disease physician in controlling antimicrobial costs in the hospital. Clin. Infect. Dis., 24: 471-485.

[3] Rajbhandare, S.S., S.M. Marks and N.N. Bock. 2004. Costs of patients hospitalized for multidrug-resistant tuberculosis. Int. J. of Tuberc. Lung D., 8: 1012-1016.

[4] Hart, C.A. and S. Kariuki, 1998. Antimicrobial resistance in developing countries. Brit. Med. J., 317 (7159): 647-650.

[5] Okeke, I.N., A. Lamikanra and R. Edelman, 1999. Socioeconomic and behavioral factors leading to acquired to bacterial resistance to antibiotics in developing countries. Emerg Infect. Dis., 5:18-27.

[6] Hawkey P.M. and A.M. Jones. 2009. The changing epidemiology of resistance. J. Antimicrob. Chemother., 64 (suppl 1): i3-10.

[7] Hiramatsu, K., H. Hanaki, T. Ino, K. Yabuta, T. Oguri, F.C. Tenover. 1997. Methicillin-resistant Staphylococcus aureus clinical strain with reduced vancomycin susceptibility. J. Antimicrob Chemother., 40: 135-6.

[8] Levy, S. B. 1998. The challenge of antibiotic resistance. Sci. Am., 278: 46-53.

[9] Einck, L., M.C. Mulvey, and K. Sacksteder. 2011. Methods and compositions for determining the pathogenic status of infectious agents, US patent No. 7919234B2, Issue date: April 5, Assignee: Sequella, Inc., USA.

[10] Lederberg, J. 2013. Nano-based Solutions to Combat the Emerging Threat of Superbugs: Current Scenario and Future Prospects. Nanotech Insights, Spotlight: 15-21.

[11] Boyce, J.M. 2005. Methicillin-resistant Staphylococcus aureus. Lancet Infect Dis., 5: 653-663.

[12] Calfee D.P., L.J. Durbin, T.P. Germanson, D.M.Toney, E.B. Smith, and B.M. Farr. 2003. Spread of Methicillin-resistant Staphylococcus aureus (MRSA) among household contacts of individuals with nosocomially acquired MRSA. Infection Control Hosp Epidemiol., 24: 422-426.

[13] Naimi, T.S., K.H. LeDell, K. Como-Sabetti, S.M. Borchardt, D.J. Boxrud, J. Etienne, S.K. Johnson, F. Vandenesch, S. Fridkin, C. O’Boyle, R.N. Danila and R. Lynfield. 2003. Comparison of community- and health care-associated methicillin resistant Staphylococcus aureus infection. JAMA, 290: 2976-2984. 
[14] Udo, E.E., Pearman, J.W. and Grubb, W.B. 1993. Genetic analysis of community isolates of methicillin-resistant Staphylococcus aureus in Western Australia. J. Hosp. Infect., 25: 97-108.

[15] Centre for Disease Control and Prevention. Update: Staphylococcus aureus with reduced susceptibility to vancomycin- United States, 1997. MMWR Morb Mortal Wkly Rep., 46: 813-815.

[16] Huttner, A., S. Harbarth, J. Carlet, S. Cosgrove, H. Goossens,, A. Holmes, V. Jarlier, A.Voss, D .Pittet. 2013. Antimicrobial resistance: a global view from 2013 World Healthcare- Associated Infections Forum, Antimicrobial Resistance and Infection Control, 2: 31.

[17] Watanabe, T. 1963. Infective heredity of multidrug resistance in bacteria. Bacteriol. Rev., 27: 87115.

[18] Brolund, A., P.J. Edquist, B. Makitalo, B. Olsson-Liljequist, T. Soderblom, K.T. Wisell, and C.G. Giske, 2013. Epidemiology of ESBL-producing Escherichia coli in Sweden 2007-2011. Clin. Microiol. Infect., 20(6): 0344-0352.

[19] Colpan, A., B. Johnston, S. Porter, C. Clabots, R. Anway, L. Thao, M.A. Kuskowski,.., V. Tchesnokova, , E.V. Sokurenko, J.R. Johnson. 2013. Escherichia coli sequence type 131(ST 131) subclone $\mathrm{H} 30$ as an emergent multidrug-resistant pathogen among US veterans. Clin. Infect Dis., 57(9): 1256-1265.

[20] Kanj, S.S. and Z.A. Kanafani. 2011. Current concepts in antimicrobial therapy against resistant Gram-negative organisms: Extended-spectrum $\beta$-lactamase-producing Enterobacteriaceae, carbapenem resistant Enterobacteriaceae and multidrug-resistant Pseudomonas aeruginosa. Mayo Clin Proc., 86(3): 250-259.

[21] Shah, N.S., G. Wright, L. Bai, F. Barrera, N. Boulahbal, F. Martin-Casabona, C. Drobniewski, M. Gilpin, R. Havelkova, R. Lepe, B. Lumb, F. Metchock, M.F. Portaels, S. Rodrigues, A.V. Rusch-Gerdes, V. Deun, K. Vincent, C.W. Laserson, and J.P. Cegielski. 2007. Worldwide emergence of extensively drug-resistant tuberculosis. Emerg. Infect. Dis.,13: 380-387.

[22] Sotgiu, G., A. Ferrara, M.D. Matteelli, R.C. Richardson, R. Centis, S. Ruesch-Gerdes, O. Toungoussova, J.P. Zellweger, A. Spanevello, D. Cirillo, C. Lange and G.B. Migliori. 2009. Epidemiology and clinical management of XDR-TB: a systematic review by TBNET. Eur. Respir. J., 33: 871-881.

[23] Velayati, A.A., M.R. Masjedi, P. Farnia, P. Tabarsi, J. Ganavi, A.H. ZiaZarifi and S.E. Hoffner. 2009. Emergence of new forms of totally drug-resistant tuberculosis bacilli: super extensively drug-resistant tuberculosis or totally drug-resistant strains in Iran. Chest, 136: 420-425.

[24] Pillay, M. and Sturm, A.W. 2007. Evolution of the Extensively Drug- Resistant F15/LAM4/KZN Strain of Mycobacterium tuberculosis in KwaZulu-Natal, South Africa. Clinical Infectious Diseases, 45: 1409-14.

[25] Ganguly, Subha, Wakchaure, Rajesh, Para, Parveez Ahmad, Praveen, Praveen Kumar, Sahoo, Saraswat, Mahajan, Tanvi, Qadri, Kausar and Kamble, Shweta (2016) MDR Bacteria: A Review of immense relevance in Veterinary Microbiology. J. Bioinnov., 5(3): 319-324.

[26] Levy, S.B. and R.V. Miller. 1989. Gene Transfer in the Environment, McGrew Hill, New York.

[27] Levy, S.B. 1985. Ecology of plasmids and unique DNA sequences In: Engineered Organisms in the Environment: Scientific Issues. Eds. Halvorson, H,O., Pramer, D. and Rogul, M., ASM Press, Washington DC. , pp. 180-190.

[28] Levy, S.B. 2002. The Antibiotic Paradox: How Misuse of Antibiotics Destroys their Curative Powers, Perseus Cambridge.

[29] Wang, H., Dzink-Fox, J.L., Chen, M. and Levy, S.B. 2001. Genetic characterization of highly fluoroquinolone-resistant clinical Escherichia coli strains from China: role of acr R mutations. Antimicrob. Agents Chemother., 45: 1515-1521.

[30] Ryan, K., C.G. Ray, N. Ahmad, W.L. Drew, J. Plorde. 2010. Sherris Medical Microbiology. $5^{\text {th }}$ edition, The McGrew Hill Companies.

[31] Arias, C.A. and B.E. Murray. 2009. Antibiotic- Resistant Bugs in the $21^{\text {st }}$ Century- A Clinical Super- Challenge. New England Journal of Medicine, 360: 5.

[32] Peleg, A.Y. and D.C. Hooper. 2010. Hospital-acquired infections due to Gram-negative bacteria. New Engl. J. Med., 362: 1804-1813. 
[33] Kunz, A.N. and I. Brook. 2010. Emerging resistant Gram-negative aerobic bacilli in hospitalacquired infections. Chemotherapy, 56: 492-500.

[34] Palomino, J.C. and A. Martin, 2014. Drug Resistance Mechanisms in Mycobacterium tuberculosis, Antibiotics, 3: 317-340.

[35] Long, K.S., Poehlsgaard, J. Kehrenberg, C., Schwartz, S. and Vester, B. 2006. The Cfr rRNA methyltransferase confers resistance to phenicols, lincosamides, oxazolidones, pleuromutillins and streptogramin A antibiotics. Antimicrob. Agents Chemother., 50: 2500-2505.

[36] Usluer, G., I. Ozgunes and H. Leblebicioglu. 2005. A multicenter point-prevalence study: antimicrobial prescription frequencies in hospitalized patients in Turkey. Ann. Clin. Microbiol. Antimicrob., 4:16.

[37] Olivier, C., B. Williams-Jones, B. Douze, and V. Ozdemir. 2010. Containing Global Antibiotic Resistance: Ethical Drug Promotion in the Developing World. Antimicrobial Resistance in Developing Countries, Springer, Chapter 29. pp. 505-524.

[38] Rollin, B. 2001. Ethics, Science and antimicrobial resistance. J Agric Environ Ethics, 14: 29-37.

[39] Barza, M. and Gorbach, S.l. 2001. The need to improve antimicrobial use in agriculture: ecological and human health consequences. Clin. Infect. Dis., 34: S71- 144.

[40] World Health Organization (WHO). 2001. Pharmaceutical promotion. In: WHO global strategy for containment of antimicrobial resistance. Executive Summary, World Health Organization (Ed.). Geneva; World Health Organization, pp: 51-53.

[41] Alekshun, M.S.B.L. 2004. Targeting virulence to prevent infection: to kill or not to kill? Drug discovery Today: Therapeutic Strategies.

[42] Jarlier, V., J. Carlet, J. McGowan, H. Goossens, A. Voss, S. Harbarth, and D. Pittet. 2012. Priority actions to fight antibiotic resistance: results of an international meeting. Antimicrobial Resistance and Infection Control, 1: 17.

[43] Longo, G., L. Alonso-Sardy, L.Marques Rio, A. Bizzini, A. Trampuz, J. Notz, G. Dietler and S. Kasas. 2013. Nat. Nanotechnol., 8: 522-526.

[44] Pangule R.C., S.J. Brooks, C.Z. Dinu, S. S. Bale, S.L. Salmon, G. Zhu, D. W. Metzger, R. S. Kane and J. S. Dordick. 2010. Antistaphylococcal nanocomposite films based on enzyme-nanotube conjugates. ACS Nano, 4(7): 3993 - 4000.

[45] Chen, L.F. 2013. The changing epidemiology of methicillin resistant Staphylococcus aureus: 50 years of Superbug. American Journal of Infection Control, 41: 448-51. 